\title{
Intracardiac Migration Following Percutaneous Computed Tomography-Guided Fiducial Marker Implantation for Pulmonary Metastasis: A Rare Complication
}

\begin{abstract}
A 41-year-old female with rectal cancer and lung metastasis underwent percutaneous transthoracic placement of fiducial marker. Postprocedure scan showed the migration of one of the fiducial markers to the left ventricle. Intracardiac fiducial marker migration is a rare complication but can happen, especially with centrally located lesions. Physicians and patients should be aware of this risk.
\end{abstract}

Keywords: Fiducial marker, lung metastasis, migration, percutaneous transthoracic

\section{Introduction}

Stereotactic body radiation therapy (SBRT) is a technique that utilizes precise targeting of tumor irradiation to minimize the exposure of adjacent normal tissue. ${ }^{[1]}$ SBRT is used to treat a variety of primary and metastatic tumors of the lung, liver, pancreas, kidney, spine, and prostate..$^{[2]}$ Fiducial markers enable lesion tracking, but complications from insertion may occur. ${ }^{[3]}$

Fiducial markers act as an internal radiological landmark and move with a constant relationship to the targeted tumor during therapy for the precise delivery of radiation.

Percutaneous implantation of fiducial markers can be achieved with a relatively low rate of major complications. Complications from fiducial marker insertion have been reported, including pneumothorax in $33 \%-68 \%$ of patients as well as bleeding. ${ }^{[4,5]}$ Fiducial markers may also migrate into the pleural space, the airway, or into the vascular structures. ${ }^{[3,6-8]}$ Intracardiac migration is an extremely rare complication. Here, we report a case of left ventricular migration of the fiducial following percutaneous implantation of the marker in a centrally located lung lesion.

\section{Case Report}

A 41-year-old female patient with rectal cancer and lung metastasis underwent

This is an open access journal, and articles are distributed under the terms of the Creative Commons Attribution-NonCommercial-ShareAlike 4.0 License, which allows others to remix, tweak, and build upon the work non-commercially, as long as appropriate credit is given and the new creations are licensed under the identical terms.

For reprints contact: reprints@medknow.com percutaneous transthoracic placement of fiducial markers in the left upper lobe lesion under computed tomography (CT) guidance. Four gold markers and one platinum coil were placed in the lung within the vicinity of the metastatic nodule in the left upper lobe. Minor perilesional bleeding was noted. Four days later, the patient underwent another percutaneous transthoracic placement of fiducial markers in bilateral metastatic lung lesions. The preprocedure scan showed mild left-sided pneumothorax, stable position of the previously inserted fiducials in the left upper lobe metastatic nodule. Three additional markers were placed in the right middle lobe metastatic lesion [Figure 1] with moderate right-sided pneumothorax. Furthermore, three markers were placed at the left lower lobe metastatic nodule and two at the right lower lobe metastatic pulmonary nodule [Figure 2]. Postprocedure scan showed the migration of one of the fiducials to the left ventricle by embolization through a pulmonary vein [Figure 3]. Follow-up CT scan at 4 months showed stable migrated fiducial in the left ventricle. The migrated fiducial markers remained stable in position at 3-year follow-up CT scan [Figure 4], when the patient expired due to the progression of the pulmonary and osseous metastasis.

\section{Discussion}

Fiducial marker migration to the heart is a rare complication that can happen,

\footnotetext{
How to cite this article: Alhindi D, Al Zahrani YA, Khankan A. Intracardiac migration following percutaneous computed tomography-guided fiducial marker implantation for pulmonary metastasis: A rare complication. Arab J Intervent Radiol 2020;4:44-6.
}

\section{Duaa Alhindi, Yousof AbdulRahman Al Zahrani ${ }^{1}$, Azzam Khankan ${ }^{1}$}

King Abdulaziz Medical City, Ministry of National Guard, ${ }^{1}$ Department of Medical Imaging, Division of Vascular and Interventional Radiology, King Abdulaziz Medical City, Ministry of National Guard - Health Affairs, Riyadh, Saudi Arabia

Received: $29-10-2019$

Revised: 04-11-2019

Accepted: 14-11-2019

Published Online: 18-12-2019

Address for correspondence: Dr. Yousof AbdulRahman Al Zahrani,

Department of Medical Imaging, Division of Vascular and Interventional Radiology, King Abdulaziz Medical City, Ministry of National Guard - Health Affairs, P.O Box 22490, Riyadh 11426, Saudi Arabia. E-mail:yousof1403@hotmail. com

Access this article online Website: www.arabjir.com DOI: 10.4103/AJIR.AJIR_29_19 Quick Response Code:

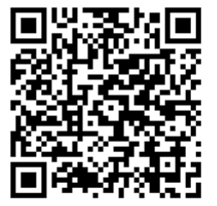




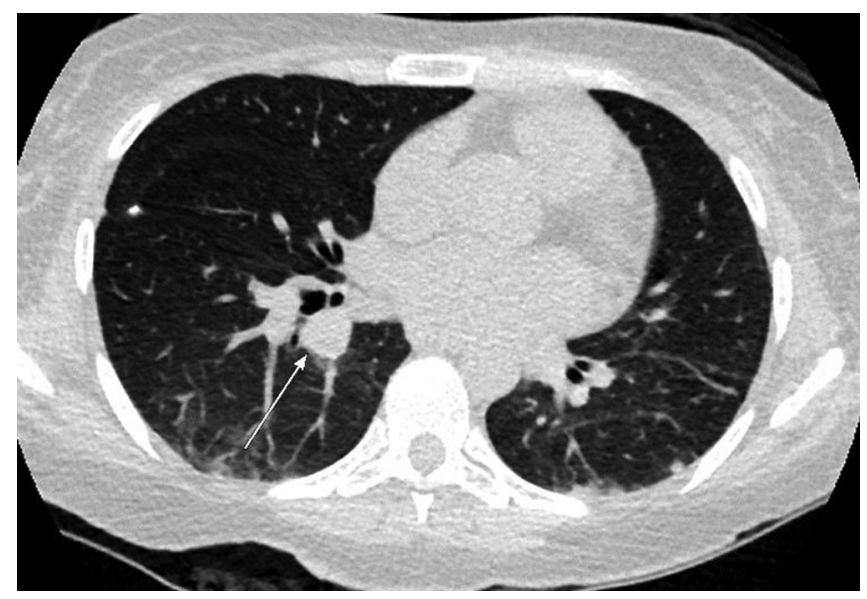

Figure 1: Computed tomography image showing centrally located metastatic pulmonary nodule was planned for fiducial marker placement

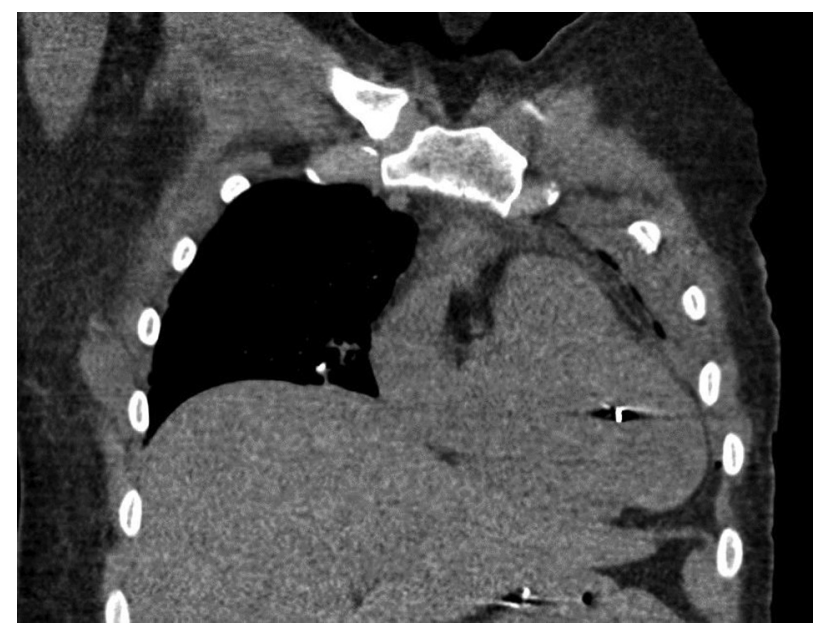

Figure 3: Unenhanced computed tomography image in coronal reformat obtained immediately after the producer shows the displacement of the marker (arrow)

especially with centrally located lung lesions. Cousin et al. reported a case of intracardiac displacement of the fiducial marker into the left atrium 1 month after the procedure, which further migrated into the left ventricle on follow-up CT. ${ }^{[7]}$ Hennessey et al. reported a case of coil migration through hepatic vein to the inferior vena cava and lodged at the cavoatrial junction during fiducial marker placement for hepatic metastasis. The coil was successfully retrieved and the patient remained asymptomatic. ${ }^{[8]}$ Farkas et al. reported another case of intracoronary fiducial migration resulting in acute coronary syndrome and was treated conservatively. ${ }^{[9]}$ In our case, the fiducial was embedded and endothelized in the ventricular wall and did not require any further intervention.

Interventional radiologists, radiation oncologists, and patients should be aware of this risk. Migration carries the risk of stroke, acute coronary syndrome, or distal embolization in other organs. In case of intracardiac migration, close observation and imaging follow-up to ensure the stability of the fiducial is highly recommended.

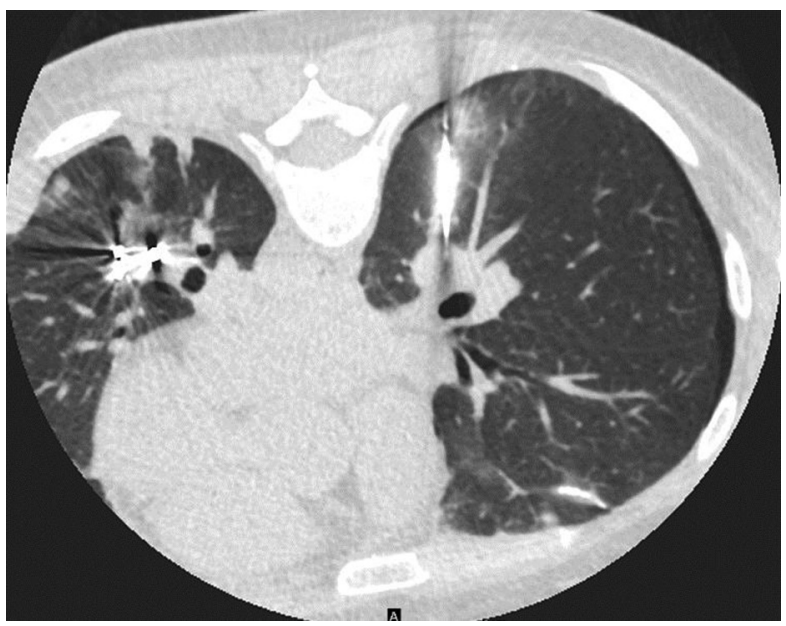

Figure 2: Unenhanced computed tomography image in the prone position during fiducial marker implantation

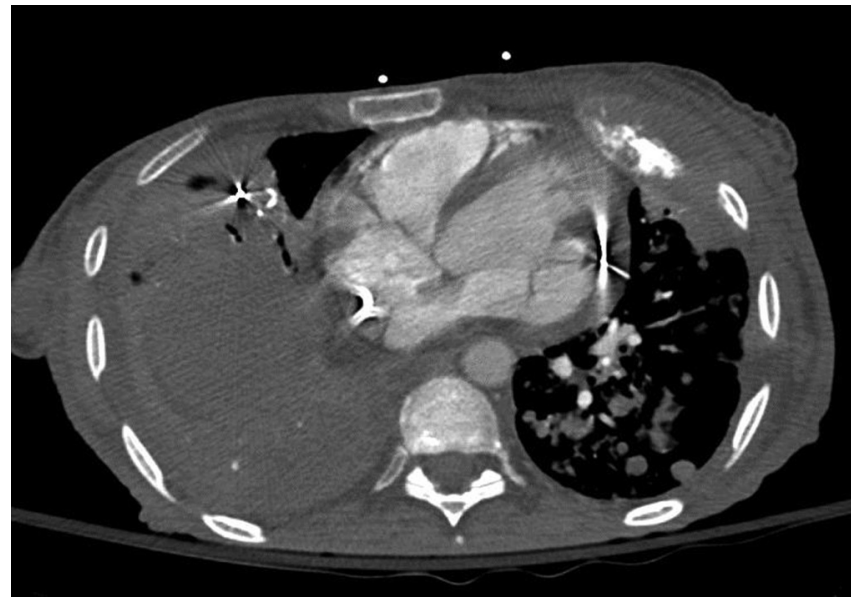

Figure 4: Enhanced computed tomography image of the chest obtained at a 3-year follow-up shows the marker stabilized in the left ventricle (arrow) as well as new metastatic pulmonary nodules

\section{Declaration of patient consent}

The authors certify that they have obtained all appropriate patient consent forms. In the form the patient(s) has/have given his/her/their consent for his/her/their images and other clinical information to be reported in the journal. The patients understand that their names and initials will not be published and due efforts will be made to conceal their identity, but anonymity cannot be guaranteed.

\section{Financial support and sponsorship}

Nil.

\section{Conflicts of interest}

There are no conflicts of interest.

\section{References}

1. Lax I, Blomgren H, Näslund I, Svanström R. Stereotactic radiotherapy of malignancies in the abdomen. Methodological aspects. Acta Oncol 1994;33:677-83.

2. Pawa S, Ehrinpreis M, Mutchnick M, Janisse J, Dhar R, 
Siddiqui FA. Percutaneous liver biopsy is safe in chronic hepatitis $\mathrm{C}$ patients with end-stage renal disease. Clin Gastroenterol Hepatol 2007;5:1316-20.

3. Bhagat N, Fidelman N, Durack JC, Collins J, Gordon RL, LaBerge JM, et al. Complications associated with the percutaneous insertion of fiducial markers in the thorax. Cardiovasc Intervent Radiol 2010;33:1186-91.

4. Kothary N, Heit JJ, Louie JD, Kuo WT, Loo BW Jr, Koong A, et al. Safety and efficacy of percutaneous fiducial marker implantation for image-guided radiation therapy. J Vasc Interv Radiol 2009;20:235-9.

5. Yousefi S, Collins BT, Reichner CA, Anderson ED, Jamis-Dow C, Gagnon G, et al. Complications of thoracic computed tomography-guided fiducial placement for the purpose of stereotactic body radiation therapy. Clin Lung Cancer
2007;8:252-6.

6. Kothary N, Heit JJ, Louie JD, Kuo WT, Loo BW Jr, Koong A, et al. Safety and efficacy of percutaneous fiducial marker implantation for image-guided radiation therapy. J Vasc Interv Radiol 2009;20:235-9.

7. Cousin F, Gérard L, Joskin J. Left Cardiac Migration of a Lung Fiducial Marker. J Vasc Interv Radiol 2019;30:445.

8. Hennessey H, Valenti D, Cabrera T, Panet-Raymond V, Roberge D. Cardiac embolization of an implanted fiducial marker for hepatic stereotactic body radiotherapy: A case report. J Med Case Rep 2009;3:140.

9. Farkas EA, Stoeckel DA, Nassif AS, Lim MJ, Naunheim KS. Intracoronary fiducial embolization after percutaneous placement for stereotactic radiosurgery. Ann Thorac Surg 2012;93:1715-7. 